\title{
Practice
}

\section{What Should Change in Nursing Practice Over the Next Five Years?}

\author{
Esther Green, RN, MSc (T) \\ Chief Nursing Officer and Director, Health Human Resource Planning \\ Cancer Care Ontario, Toronto
}

The past decade has witnessed so many social, technological and economic alterations, renovations and revolutions that a new norm has emerged in healthcare. This new norm is constant and unrelenting change. Further change will likely be the reality in the next decade, also. Consider that the "baby boomers," by the year 2020, will be the "new" elderly. Lifespan will continue to increase. The growth and development of non-North American economies will increasingly challenge our own. Technological and radical biological scientific discoveries will be part of the new norm. While many decry the pace and complexity of change, this commentary suggests, perhaps ironically, that even more change should take place, specifically in the nursing profession.

Even though the healthcare system has attempted to manage change throughout the past few years, the Ontario experience with Severe Acute Respiratory Syndrome (SARS) graphically brought to light "what should change" in order to sustain a responsive healthcare (and illness care) system.
What became apparent was the need for intersectoral collaboration, consistency and superior systems of internal and external communications for a number of issues, from basic infection control to public education. With SARS and other potential threats from viruses not yet known, attention should focus on the role of nurses for surveillance, prevention and management of patient care across the system. Here is an opportunity for nursing leadership, practice and education to influence policy development within the health system.

This milieu of change may prove to be an opportune time for nursing to step up the pace of professional innovation and advancement. Nursing practice should be focused on the area of specialization and seize the opportunity for creating innovative new roles within the current system. This focus will require agreement and shared goals between care organizations and educational programs.

Notwithstanding the emphasis on basic general knowledge, opportunities for specialization should be introduced 
at the undergraduate level. Refinement of advanced skills and roles will be situated in post-graduate programs. The development of the skilled generalist, as well as the specialist, will force new levels of collaboration and innovation in academic programs. Our professional regulatory frameworks should include, along with the primary healthcare nurse practitioners, mechanisms for the standards, title and licensing of emerging specialists such as acute care nurse practitioners. To support the move, leaders should make full use of published evidence regarding the outcomes associated with specialized nurses. For example, patients cared for by specialized oncology nurses have demonstrated decreased symptom distress, higher levels of functional independence, fewer hospital admissions and improved quality of life (McCorkle et al. 1989; Corner et al. 2003). These positive outcomes are attributed to individualized, holistic nursing interventions, improved patient education, application of knowledge and skills in pain and symptom management, and psychosocial support (Naylor et al. 1999; Mundinger et al. 2000; Pioro et al. 2000; Brooten et al. 2003).

The notion of advanced practice nurses (APNs) is not new to the healthcare system. Nonetheless, the concept has been slow to become established in some areas. In some domains, APNs are used as physician extenders or substitutions. APN implementation has been successful in settings where there has been careful assessment of the environment, detailed planning for the nurses' introduction and strong nursing leadership to support the role (Sidani et al.
2000). The need for advanced practice nurses will continue to grow. While there are many opportunities for APN practice, there is more work to be done to ensure that the roles are legitimized through regulation, legislation, educational programs and credentialling. A clear and consistent vision for APN practice with respect to patients, physicians, administrators, other clinicians and policy makers will determine how advanced practice should change. The full domains of the APN role must be sustained in the practice settings to include not only comprehensive care, but also the utilization of nurses' leadership, scholarly and change-management potential.

Professional practice environments should change. In the past, nurses have functioned in a practical, division-oflabour model that is no longer appropriate. Nurses, as strong and vital professionals, possess cognitive knowledge, advanced skills, systems understanding and self-motivated creativity (Quinn 1996). Nurses also have scientific and technical knowledge, critical thinking and decision-making skills; they provide individualized, holistic care and integrate research into practice. To maximize the potential of nurses as knowledge workers, we need to encourage autonomy, empower individuals to use their creative talents and adopt contemporary leadership styles. Nurses must be valued for their unique contributions to the system and recognized for their ability to adopt, and adapt to, change - not only in patient populations but also in healthcare delivery.

The Canadian Nursing Advisory 
Committee (CNAC) identified 51 recommendations addressing factors that would improve the work environments for Canadian nurses, including operational workforce (i.e., workload, resources), professional practice (i.e., leadership, respect, autonomy) and knowledge transition (i.e., continuing education, information dissemination) (CNAC 2002). Changes in the workplace that are consistent with these recommendations should change practice, where nurses are supported and encouraged to become autonomous leaders in patient care. The notion of collaborative practice should dominate all practice settings. Nurses should take the lead in breaking down the practice silos between disciplines and in creating safe, effective patient- and familycentred care.

Practice models should change to reflect the needs of the individuals whom nurses could and should be serving. In response to compelling health problems and needs within vulnerable populations in remote or underserviced areas (rural or urban), nurseled clinics should be fostered, implemented and evaluated. Barriers such as hospital or community by-laws, legislation and policy should be overcome to allow for nursing services to those in need. Recent studies demonstrate the positive impact on the quality of patient care when nurses are supported in independent practice (Loftus and Weston 2001; Moore et al. 2002). Nurses have taken on functional elements within the system, often in relation to another

\section{A great choice. A fulfilling career.}

When you choose the Faculty of Nursing, University of Alberta, you are choosing one of the top nursing programs in the country with an international reputation for being a leader in teaching, research, and public service. We offer an exceptional and flexible educational experience.

Consider our graduate programs.

Master of Nursing Program - This program prepares nurses for leadership roles in nursing practice, nursing education, and health care. Check our website.

PhD in Nursing Program - This research based program prepares candidates to advance nursing knowledge.

For more information, contact:

Graduate Services

Faculty of Nursing

University of Alberta

4-111 Clinical Sciences Building

Edmonton, Alberta Canada T6G 2G3

Telephone: (780) 492-6251

Fax: (780) 492-2551

Toll Free: 1-888-492-8089

Email: graduate@nursing.ualberta.ca

www.nursing.ualberta.ca

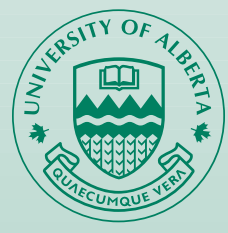

Start your program in May, September, or January.

discipline's limited availability.

There is a compelling opportunity to re-examine the system from the aspect of accessibility and waiting times.

Nurses with advanced knowledge and skills could work in specialized diagnostic units, ensuring improved throughput of patients while offering them comprehensive assessment, counselling and teaching (Schoenfeld et al. 1998). The situations of practice change should be based on identified needs of patient populations within the realm of evidence-based practice, but not in relation to substitution or replacement of another discipline.

Finally, the role of nurses in highlevel policy development will continue to have profound effects on practice. With the establishment of several nurs- 
ing policy and research units across the country, all aspects of nursing, practice, education, leadership and research have been strengthened. Nursing practice, administration and education should be based on the best evidence available, and we should develop support for mechanisms that successfully transfer knowledge into practice and policy.

It appears that high-velocity change and transformation is our inevitable new norm. While nursing has been in the position of responding to profound change over the past decade, it is now time for the profession to lead the next generation of change to effect new roles, practice environments, care models and policy decisions that contribute to a healthy population of Canadians and a model healthcare system. Assuring collective support for a new norm and vision within the profession and beyond will be nursing leaders' challenge and imperative.

I would like to acknowledge Dr. Janet Rush, who critiqued this paper and gave insightful suggestions.

\section{References}

Brooten, D., M. Naylor, R. York, L. Brown, B. Hazard Munro, A. Hollingsworth, S. Cohen, S. Finkler, J. Deatrick and J. Youngblut. 2003. "Lessons Learned from Testing the Quality Cost Model of Advanced Practice Nursing (APN) Transitional Care." Journal of Nursing Scholarship 34(4): 369-75.

Canadian Nursing Advisory Committee. 2002. Our Health, Our Future: Creating Quality Workplaces for Canadian Nurses. Ottawa: Health Canada. Retrieved November 22, 2003. $<$ http://www.hc-sc.gc.ca/english/for_you/nursing/cnac_report/index.html $>$.

Corner, J., D. Halliday, J. Haviland, H.R. Douglas, P. Bath, D. Clark, C. Normand, N. Beech, B. Hughes, R. Marples, J. Seymour, J. Skilbeck and T. Webb. 2003. "Exploring Nursing Outcomes for
Patients with Advanced Cancer Following Intervention by Macmillan Specialist Palliative Care Nurses." Journal of Advanced Nursing 41(6): 561-74.

Loftus, L. and V. Weston. 2001. “The

Development of Nurse-Led Clinics in Cancer Care." Journal of Clinical Nursing 10: 215-20.

McCorkle, R., J. Benoliel, G. Donaldson, F. Georiadou, C. Moinpour and B. Goodall. 1989. "A Randomized Control Trial of Home Nursing Care for Lung Cancer Patients." Cancer 64(6): 1375-82.

Moore, S., J. Corner, J. Haviland, M. Wells, E. Salmon, C. Normand, M. Brada, M. O'Brien and I. Smith. 2002. "Nurse-Led Follow-up and Conventional Medical Follow-up in Management of Patients with Lung Cancer: Randomized Trial." British Medical Journal 325: 1-7.

Mundinger, M., R. Kane, E. Lenz, A. Totten, W. Tsai, P. Cleary, W. Friedewald, A. Siu and M. Shelanski. 2000. "Primary Care Outcomes in Patients Treated by Nurse Practitioners or Physicians." Journal of the American Medical Association 283: 59-68.

Naylor, M., D. Brooten, R. Campbell, B. Jacobsen, M. Mezey, M. Pauly and J. Schwartz. 1999.

"Comprehensive Discharge Planning and Home Follow-up of Hospitalized Elders: A Randomized Clinical Trial." Journal of the American Medical Association 281: 613-20.

Pioro, M., M. Landefeld, P. Brennan, B. Daly, R. Fortinsky, U. Kim and G. Rosenthal. 2001.

"Outcomes-Based Trial of an Inpatient Nurse Practitioner Service for General Medical Patients." Journal of Evaluation in Clinical Practice 7(1): 21-33.

Quinn, J., P. Anderson and S. Finkelstein. 1996.

"Managing Professional Intellect: Making the

Most of the Best." Harvard Business Review 74(2): 71-80.

Schoenfeld, P., M. Johnston, M. Piordowski, D. Jones, M. Eloubeidi and D. Provenzale. 1998. "Effectiveness and Patient Satisfaction with Nurse-Directed Treatment of Barrett's Esophagus." American Journal of Gastroenterology 93(6): 906-10.

Sidani, S., D. Irvine, H. Porter, L. O’Brien-Pallas, B. Simpson, L. McGillis-Hall, L. Nagel, J. Graydon, A. DiCenso and D. Redelmier. 2000. "Practice Patterns of Acute Care Nurse Practitioners." Canadian Journal of Nursing Leadership 13: 6-12. 